\title{
A Drosophila Receptor Tyrosine Phosphatase Expressed in the Embryonic CNS and Larval Optic Lobes Is a Member of the Set of Proteins Bearing the "HRP" Carbohydrate Epitope
}

\author{
Chand J. Desai, Evgenya Popova, and Kai Zinn \\ Division of Biology, California Institute of Technology, Pasadena, California 91125
}

\begin{abstract}
Recent studies have defined several cell surface glycoproteins expressed in the developing nervous system of insect embryos that may be involved in axon outgrowth and guidance processes. These glycoproteins include the fasciclins and a group of receptor-linked protein tyrosine phosphatases (R-PTPs). In embryos, the fasciclins are localized to axonal subsets, while the R-PTPs appear to be expressed on most or all CNS axons. To identify other neuronal cell surface glycoproteins in the Drosophila embryo, we have taken a biochemical approach. This is based on the observation that antisera against horseradish peroxidase (HRP) recognize a carbohydrate epitope that is selectively expressed in the insect nervous system. A large number of neuronal glycoproteins (denoted "HRP proteins") apparently bear the HRP carbohydrate epitope. We have used polyclonal anti-HRP antibodies to purify these proteins from Drosophila embryos, and have obtained protein sequences from seven HRP protein bands. These data define three major HRP proteins as neurotactin, fasciclin I, and an R-PTP, DPTP69D. Western blotting data suggest that fasciclin II, neuroglian, DPTP10D, and DPTP99A are also HRP proteins. We show that DPTP69D, like the previously characterized R-PTPs, is localized to CNS axons in the embryo. In third instar larvae, DPTP69D expression is restricted to subsets of neuronal processes in the brain, ventral nerve cord, and eye disk. In the optic lobes, DPTP69D is localized to the neuropils of the lamina and medulla, and to an array of parallel thick bundles that may be the transmedullary fibers of the developing lobula complex.
\end{abstract}

\footnotetext{
Received Feb. 25, 1994; revised May 19, 1994; accepted May 26, 1994.

We thank David Teplow (Caltech Microchemical Facility) and Hediye Erdjument-Bromage and Paul Tcmpst (Sloan-Kettering Memorial Cancer Center, New York) for protein sequencing. We thank Susan Ou and the Caltech monoclona antibody facility for performing MAb fusions. We also thank Ron Davis and Kyung-An Han (Baylor University) for the M60 enhancer trap line and for helpful discussions, Suma Datta, Konrad Zinsmaier, Doris Kretzschmar, Simona Tix, Paul Garrity, and Howard Lipshitz for discussions concerning the DPTP69D optic lobe expression pattern, Mark Seeger for discussions on PTP genetics, Rosalind Young for help with sectioning, Nancy Bonini for the larval brain immunohistochemistry protocol, Barry Condron for help with confocal microscopy, Michel Piovant for the FA4 MAb, Corey Goodman for the 1D4 MAb, and Shin-Shay Tian for performing the in situ hybridization. C.J.D. was supported by a postdoctoral fellowship from the American Cancer Society. This work was supported by a grant (NS28182) from the NIH to K.Z., as well as by a Pew Scholars Award a McKnight Scholars Award, and a Basil O'Connor Starter Scholars Award (5816) from the March of Dimes Birth Defects Foundation.

Correspondence should be addressed to Kai Zinn, 216-76 California Institute of Technology, Pasadena CA 91125.

Copyright (C) 1994 Society for Neuroscience $0270-6474 / 94 / 147272-12 \$ 05.00 / 0$
}

[Key words: protein tyrosine phosphatases, adhesion molecules, fasciclins, carbohydrate epitope, axonal glycoproteins, Drosophila CNS, Drosophila optic lobes]

During the development of the insect nervous system, the growth cones of pioneer neurons navigate over the surfaces of neuroepithelial and glial cells. Neurons arising later in development often extend growth cones along pathways formed by preexisting axons. The segmental ganglia in the embryonic insect CNS provide a good system in which to study the navigation of growth cones along these stereotyped pathways, because they contain a small number of neurons that make genetically defined pathway decisions during development.

A number of cell adhesion molecules that may be involved in axon outgrowth and guidance processes have been identified in grasshopper and Drosophila. Neuroglian and neurotactin are proteins that are expressed on most or all axons in the embryonic Drosophila CNS, while the fasciclin glycoproteins are expressed on specific subsets of axons. Fasciclins I, II, III, and neuroglian have all been shown to be capable of functioning as homophilic adhesion molecules (reviewed by Grenningloh et al., 1990), while neurotactin is a heterophilic adhesion molecule (Barthalay et al., 1990).

Another class of axonal glycoproteins are signal transduction molecules involved in the control of tyrosine phosphorylation. These include three receptor-linked protein tyrosine phosphatases (R-PTPs; reviewed by Zinn, 1993) and a receptor-linked tyrosine kinase (Pulido et al., 1992). Each of these proteins has an extracellular domain containing immunoglobulin-like (Ig) and/or fibronectin type III (FN) modules related to those found in neural adhesion molecules such as N-CAM, L1, fasciclin II, and neuroglian.

Antisera against horseradish peroxidase (HRP) cross-react with an epitope expressed on neuronal cell bodies and axons in insects (Jan and Jan, 1982). This epitope is a specific carbohydrate moiety (Snow et al., 1987; Katz et al., 1988). When anti-HRP antibodies are used for immunoprecipitation or Western blotting experiments with lysates from insect embryos, a large number of protein bands are visualized. In the grasshopper, two of these "HRP proteins" were shown to be fasciclin I and II (Snow et al., 1987). These data suggested that a large number of different insect adhesion/recognition molecules may bear the HRP carbohydrate epitope.

To biochemically characterize Drosophila neuronal glycoproteins bearing the HRP epitope, we used anti-HRP antibodies as affinity reagents to purify HRP proteins from embryo lysates. We obtained protein sequence information from seven bands 
in the purified preparation. These data show that the three most abundant HRP protein species are neurotactin, fasciclin I, and an R-PTP, DPTP69D. Western blotting data suggest that fasciclin II, neuroglian, and two other R-PTPs are also HRP proteins. We generated monoclonal antibodies (MAbs) against DPTP69D and show that, like the previously characterized R-PTPs, it is selectively expressed on CNS axons in the embryo. In third instar larvae, it is expressed in the brain and ventral nerve cord and on the photoreceptor axons. In the optic lobes, DPTP69D is localized to neuropils of the lamina, medulla, and lobula complex. It is also expressed on a columnar array of neuronal processes.

\section{Materials and Methods}

Purification of HRP proteins. Antibodies recognizing carbohydrate epitopes were purified from commercial rabbit or goat anti-HRP antiserum (Cappel) by incubating the sera [buffer: $20 \mathrm{~mm}$ sodium phosphate (pH 7.3), $140 \mathrm{~mm} \mathrm{NaCl}$ ] with immobilized pineapple bromelain (Sigma). The bromelain had been previously coupled to ECH-Sepharose (Pharmacia) and inactivated by pretreatment with $1 \mu \mathrm{g} / \mathrm{ml}$ PMSF (Sigma). After washing with TBS [ $25 \mathrm{~mm}$ Tris- $\mathrm{HCl}$ (pH 8.0), $136 \mathrm{~mm} \mathrm{NaCl}, 2.5$ $\mathrm{mm} \mathrm{KCl}$, the cross-reacting antibodies were eluted in $0.1 \mathrm{M}$ glycine buffer ( $\mathrm{pH} 2.5$ ). In a representative preparation from $100 \mathrm{mg}$ of antiHRP IgG, $3 \mathrm{mg}$ was eluted from the bromelain column. These antibodies (at $1 \mathrm{mg} / \mathrm{ml}$ of protein) were covalently attached to Affi-gel 10 beads (Bio-Rad). In a single HRP protein preparation, $10 \mathrm{gm}$ of stage 12-17 embryos (9-16 hr old) was homogenized in $40 \mathrm{ml}$ of $10 \mathrm{~mm}$ Tris- $\mathrm{HCl}$ (pH 8.0), $1 \mathrm{~mm}$ Na-EDTA plus a protease inhibitor cocktail [final concentration: $20 \mu \mathrm{g} / \mathrm{ml}$ PMSF, and $1 \mu \mathrm{g} / \mathrm{ml}$ each of antipain, aprotinin, chymostatin, leupeptin, pepstatin A, TLCK (BMB), and TPCK (Sigma)]. The homogenate was centrifuged at $300 \times g$ for $10 \mathrm{~min}$ at $4^{\circ} \mathrm{C}$, the supernatant was centrifuged again for $15 \mathrm{~min}$ at $4000 \times \mathrm{g}$, and $10 \%$ SDS was then added to the supernatant to a final concentration of $1 \%$. The embryos were solubilized by heating at $70^{\circ} \mathrm{C}$ for $15 \mathrm{~min}$. The solubilized lysate was diluted fivefold with $60 \mathrm{~mm}$ Tris- $\mathrm{HCl}(\mathrm{pH} 7.6), 1.25 \%$ Triton X-100, $180 \mathrm{~mm} \mathrm{NaCl}, 6 \mathrm{~mm}$ Na-EDTA plus the same protease inhibitor cocktail, and allowed to stand at $4^{\circ} \mathrm{C}$ for $1 \mathrm{hr}$. The resulting suspension was then centrifuged at $100,000 \times g$ for $1 \mathrm{hr}$. The supernatant was filtered through Whatman \#5 paper and a $0.2 \mu \mathrm{m}$ Polycap filter (Whatman), and applied to an anti-HRP antibody column (typically a 3-5 ml column) at a rate of about $10 \mathrm{ml} / \mathrm{hr}$. The column was washed successively with $250 \mathrm{ml}$ each of "washing solution" [ $50 \mathrm{~mm}$ Tris-HCl (pH 8.0), $150 \mathrm{~mm} \mathrm{NaCl}, 0.02 \%$ SDS, $0.1 \%$ Triton $\mathrm{X}-100,5 \mathrm{~mm} \mathrm{Na}-$ EDTA, $1 \mu \mathrm{g} / \mathrm{ml} \mathrm{PMSF}$ ], "high salt buffer" [50 mM Tris-HCl (pH 7.6), $1 \mathrm{M} \mathrm{NaCl}, 1 \mathrm{~mm}$ Na-EDTA, $1 \%$ Triton X-100, $1 \mu \mathrm{g} / \mathrm{ml} \mathrm{PMSF}$, "high pH buffer" [50 mм Tris base (pH 9), $0.5 \mathrm{~m} \mathrm{NaCl}$, 1 mм Na-EDTA, 1 $\mu \mathrm{g} / \mathrm{ml} \mathrm{PMSF}]$, and "preelution buffer" [10 mM Tris- $\mathrm{HCl}(\mathrm{pH} 6.8), 1$ mM Na-EDTA, $1 \mu \mathrm{g} / \mathrm{ml}$ PMSF]. The bound proteins were eluted with $2 \times 5 \mathrm{ml}$ of $0.1 \mathrm{M}$ glycine buffer ( $\mathrm{pH} 2.5$ ). The capacity of the columns was very low. This could be due to two factors: (1) most of the anticarbohydrate antibody on the column probably does not actually bind to the relevant anti-HRP epitope, because the epitope is likely to include only a few carbohydrate residues (see Discussion); (2) the HRP epitope may also be linked to glycolipids, and these could occupy antibody combining sites and thereby reduce the column capacity. The column eluate was neutralized with $1 \mathrm{M}$ Tris base to a final $\mathrm{pH}$ of 7.5 , and $\mathrm{NaCl}$ was added to $0.5 \mathrm{M}, \mathrm{CaCl}_{2}$ to $1 \mathrm{~mm}$, and $\mathrm{MnCl}_{2}$ to $1 \mathrm{~mm}$. Five separate anti-HRP column elutions were pooled and mixed with $0.5 \mathrm{ml}$ of concanavalin A (ConA) agarose beads (Pharmacia). ConA binds to carbohydrate moieties bearing terminal mannose groups, which are characteristic of insect glycoproteins. Sequential batches of five anti-HRP column elutions were applied to the same $0.5 \mathrm{ml}$ of ConA beads until no further adsorption of protein from the elutions could be observed.

Protein sequencing. For final purification of HRP proteins, $0.5 \mathrm{ml}$ of ConA beads was boiled in $1.5 \mathrm{ml}$ of sample buffer, and the eluted proteins applied to a $1-\mathrm{mm}$-thick, $6-15 \%$ SDS-PAGE gel. The gel was electrophoretically transferred in $0.5 \times$ running buffer with $15 \%$ methanol at $100 \mathrm{~V}$ for $2 \mathrm{hr}$ at $4^{\circ} \mathrm{C}$ to a $0.45 \mu \mathrm{m}$ nitrocellulose filter (Schleicher and Schuell) in a Hoefer transblot apparatus. Protein bands on the filters were visualized using $0.1 \%$ Ponceau $S$ (Sigma) in $1 \%$ acetic acid, excised with a razor blade, and digested in situ with trypsin (BMB sequencing grade) (Tempst et al., 1990). The resulting tryptic fragments were sep- arated on a $4.6 \mathrm{~mm}$ or a $2.1 \mathrm{~mm}$ narrow-bore reverse-phase HPLC column. Selected peaks were chosen for sequence analysis. Here, the first number is the molecular weight of the protein and the second number refers to the peak on the HPLC column profile. Sequences $135-$ $29,135-57,135-58,110-36,110-40,110-44,85-40,85-46,75-22$, and 75-62 (see Table 1) were determined at the Caltech Microchemical Facility, and sequences 85-27, 75-17, 75-29, 70-22, 70-39, 70-48, 6542, 60-20, and 60-22 were determined by Hediye Erdjument-Bromage and Paul Tempst of Sloan-Kettering Memorial Cancer Center, NY. In addition to the sequences described in the text, we also obtained three other sequences from the $85 \mathrm{kDa}$ band, two others from the $70 \mathrm{kDa}$ band, and four sequences from $55 \mathrm{kDa}$ and $43 \mathrm{kDa}$ bands. These corresponded to the known sequences of hsp82, hsp 70, mammalian IgG (which apparently dissociated from the column during elution), and yolk protein 3 (yp3), respectively. hsp82, hsp70, and yp3 are very abundant embryonic proteins which were apparently residual contaminants of the HRP protein preparation. The hsp82, hsp70, and yp3 sequences were oblained prior to the introduction of the ConA step into the purification, and this step appears to effectively remove these proteins from the preparation.

Molecular biology experiments. Molecular cloning and protein expression experiments were performed according to standard protocols (Sambrook et al., 1989). For isolation of DPTP69D cDNA clones, degenerate oligonucleotide primers based on the determined protein sequences of peptides 110-40 and 110-44 were used to PCR amplify (Saiki et al., 1988) coding sequence fragments from oligo-dT-primed cDNA made from 9-12 hr embryo RNA. These fragments were cloned and sequenced. They were then labeled with ${ }^{32} \mathrm{P}$ and used to screen a 9-12 hr $\lambda$ gt 11 cDNA library (Zinn et al., 1988).

Western blotting. Forty microliters of total embryo lysate, $40 \mu \mathrm{l}$ of anti-HRP column elution, or $50 \%$ of the immunoprecipitations (see below) were loaded per lane on 6-15\% SDS-PAGE gels, subjected to electrophoresis, and transferred to nitrocellulose as described above. The blots were blocked in blotto $(0.5 \%$ Carnation nonfat dried milk in TBS) for $30 \mathrm{~min}$, and then incubated overnight with rabbit anti-HRP antiserum (Cappel) diluted to $1: 1000$, or MAb supernatants diluted to 1:5-10. After washing with TBS, the blots were incubated with alkaline phosphatase (AP)-conjugated goat anti-rabbit IgG (Cappel) or anti-mouse IgG (Jackson), diluted 1:1000. AP activity was detected using the Genius kit (BMB).

Immunoprecipitations. To $10 \mathrm{ml}$ of crude embryo lysate, $20 \mu \mathrm{l}$ each of the anti-DPTP69D MAb supernatants $1 \mathrm{C} 2,3 \mathrm{D} 11,3 \mathrm{~F} 12,2 \mathrm{C} 2$, and 2B6 (present study), or $33 \mu$ each of the anti-fasciclin I MAb supernatants 5H7, 2A2, 1 B8 (Hortsch and Goodman, 1990), and $1 \mu \mathrm{l}$ of antifasciclin I MAb 5E1 ascites (T.-Y. Kung, W.-C. Wang, and K. Zinn, unpublished results) were added, mixed and incubated on ice. After 30 min, $10 \mu \mathrm{l}$ of rabbit anti-mouse IgG (Jackson) was added, mixed, and incubated on ice. Thirty minutes later, $40 \mu \mathrm{l}$ of TBS-washed protein A-sepharose (Pierce) was added, and each reaction was rocked for at $4^{\circ} \mathrm{C}$. After $1 \mathrm{hr}$, the protein A beads were pelleted, washed with TBS, and subjected to SDS-PAGE.

Generation of MAbs against DPTP69D. One oligonucleotide primer creating a Bcl I site and a second primer spanning a natural Bcl I site were used to PCR amplify a 1101 hp fragment from a DPTP69D cDNA clone. This PCR fragment encodes a 367 residue portion of the extracellular domain of DPTP69D. It was ligated into the BamH1 cloning site of pET-3c (Studier et al., 1990). BL21 Escherichia coli cells transformed with this construct were induced to express fusion protein, which was purified from inclusion bodies by SDS-PAGE and used to immunize mice (50-100 $\mu$ g per injection). Injections were repeated every 2 weeks, and sera were collected $7 \mathrm{~d}$ following the boosts and tested for embryo staining. A mouse with a positive serum response was used for MAb fusion. Two hundred ninety-two individual monoclonal antibodies were tested on dot blots using bacterially expressed fusion proteins (containing DPTP69D or control sequences) as antigens. Fifty-three strongly positive clones were then screened by embryo staining. Seventeen of these showed robust CNS staining in whole-mount embryos.

To facilitate the purification of HRP proteins, we also attempted to isolate a MAb against the cross-reacting HRP epitope by sequential injection of mice with HRP, bromelain, and Drosophila HRP proteins, followed by MAb fusion. However, no MAbs against the relcvant cpitope were identified from 557 that were screened.

In situ hybridization. The whole-mount digoxigenin in situ hybridization procedure (Tautz and Pfeifle, 1989) was used to localize DPTP69D transcripts. The Genius kit (BMB) was used to generate digoxigenin- 
Table 1. Protein sequence data from tryptic peptides derived from HRP proteins

HRP Protein sequence data

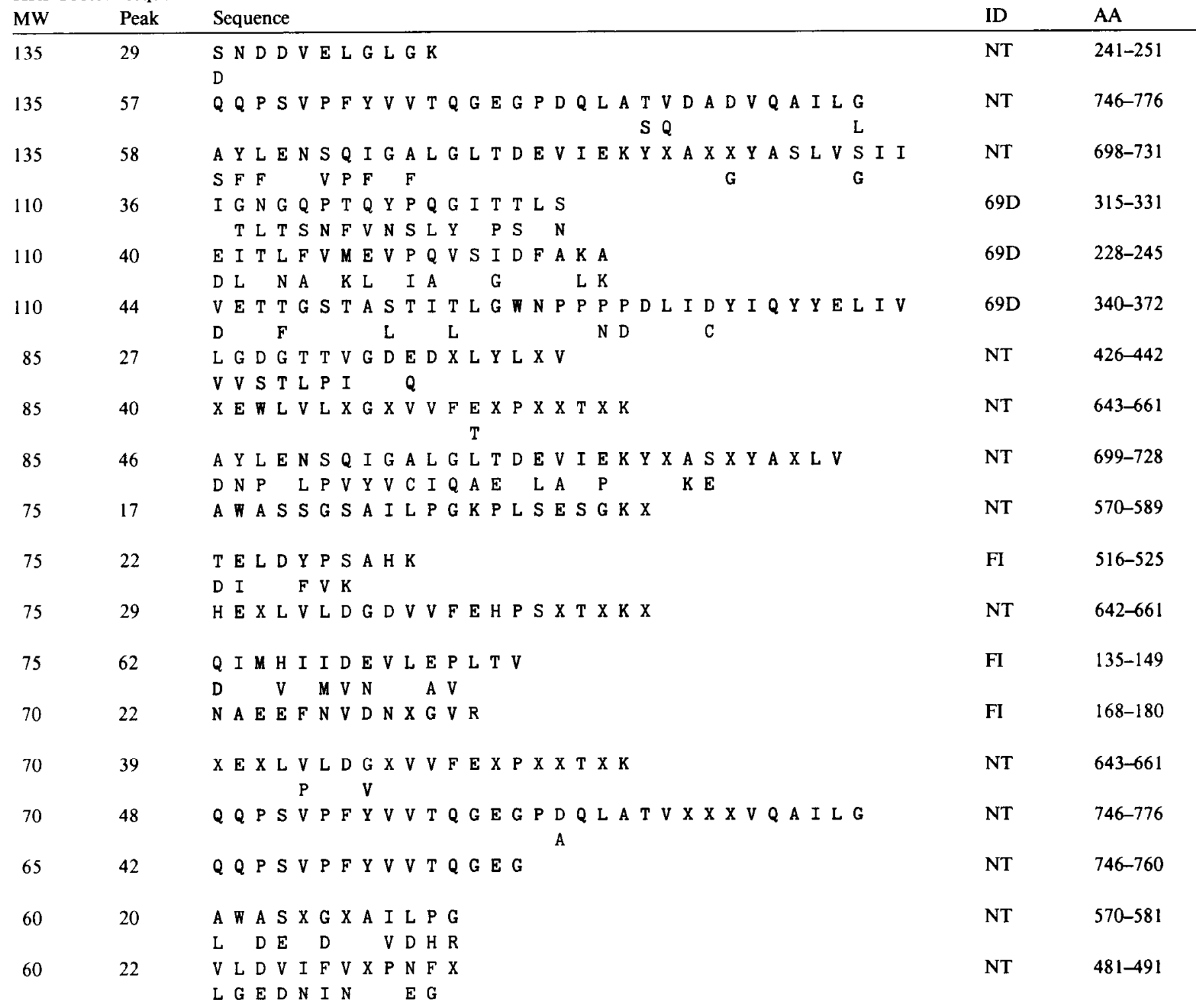

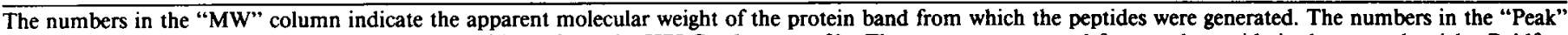

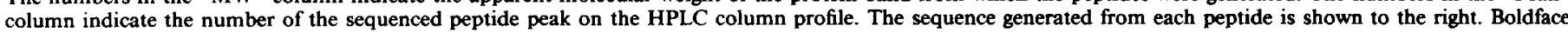

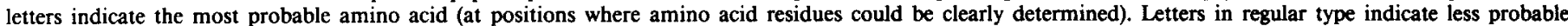

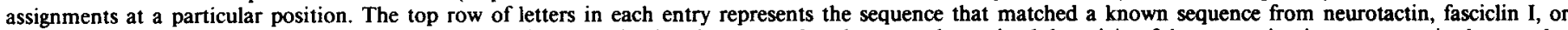

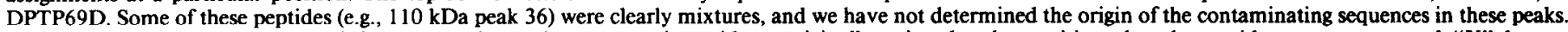

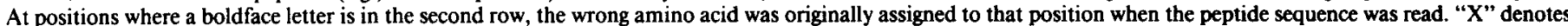

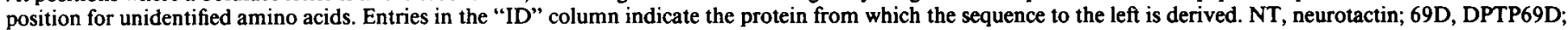
$\mathrm{FI}$, fasciclin I. The "AA" column indicates the amino acid residue numbers in the protein that correspond to the peptide sequence in that row.

labeled probe, and hybridization was detected using the Vector $A B C$ substrate kit II. Embryos were dehydrated and cleared in methyl salicylate.

Immunohistochemistry. Antibody staining of whole-mount embryos using HRP immunocytochemistry was done as described (Elkins et al., 1990). MAb supernatants were diluted $1: 5$, and anti-HRP antisera were diluted 1:200. A preparation of an anti- $\beta$-galactosidase MAb (Promega) was diluted at 1:500. Rabbit anti- $\beta$-galactosidase antibodies (Cappel) were used at 1:200. Fluorescent secondary antibodies (Cappel) were used at 1:300. For photography, nerve cords were dissected from stained whole-mounts. Larval brains were dissected in batches of 5-10 in PBS

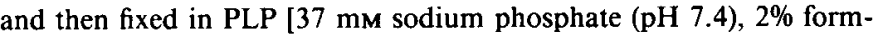
aldehyde, $1.37 \%(94 \mathrm{~mm})$ lysine, $0.21 \%(14 \mathrm{~mm}) \mathrm{NaI}$ ] for $30 \mathrm{~min}$ at RT. After washing with BSS ( $38 \mathrm{~mm} \mathrm{NaCl}, 53 \mathrm{~mm} \mathrm{KCl,} 12 \mathrm{~mm} \mathrm{MgSO}_{4}$,
$6 \mathrm{~mm} \mathrm{CaCl}, 10 \mathrm{~mm}$ tricine, $20 \mathrm{~mm}$ glucose, $50 \mathrm{~mm}$ sucrose, $0.2 \% \mathrm{BSA}$, pH 6.95), the brains were permeabilized for $30 \mathrm{~min}$ at RT with BSN (BSS $+0.2 \%$ saponin and 3\% goat serum) $+0.2 \%$ NP- 40 , and then incubated with MAb supernatant diluted 1:10 in BSN overnight at RT. After washing with BSS, the brains were incubated with HRP-conjugated goat anti-mouse IgG (diluted 1:200) for $2 \mathrm{hr}$ at RT, washed in BSS and PBS, and postfixed in $1 \%$ glutaraldehyde (Kodak) in PBS for 15-30 min. For fluorescent staining, HCHO (2\%) was used instead of glutaraldehyde for postfixing. After washing with PBS, the brains were incubated in $0.33 \mathrm{mg} / \mathrm{ml}$ diaminobenzidine (DAB) and $0.013 \% \mathrm{NiCl}$, followed by addition of $10 \mathrm{ppm} \mathrm{H}_{2} \mathrm{O}_{2}$ to start the HRP reaction. The brains, embryos, and nerve cords were photographed on a Zeiss Axioplan microscope using Nomarski optics, or were analyzed by confocal microscopy on a Bio-Rad 600 instrument. 


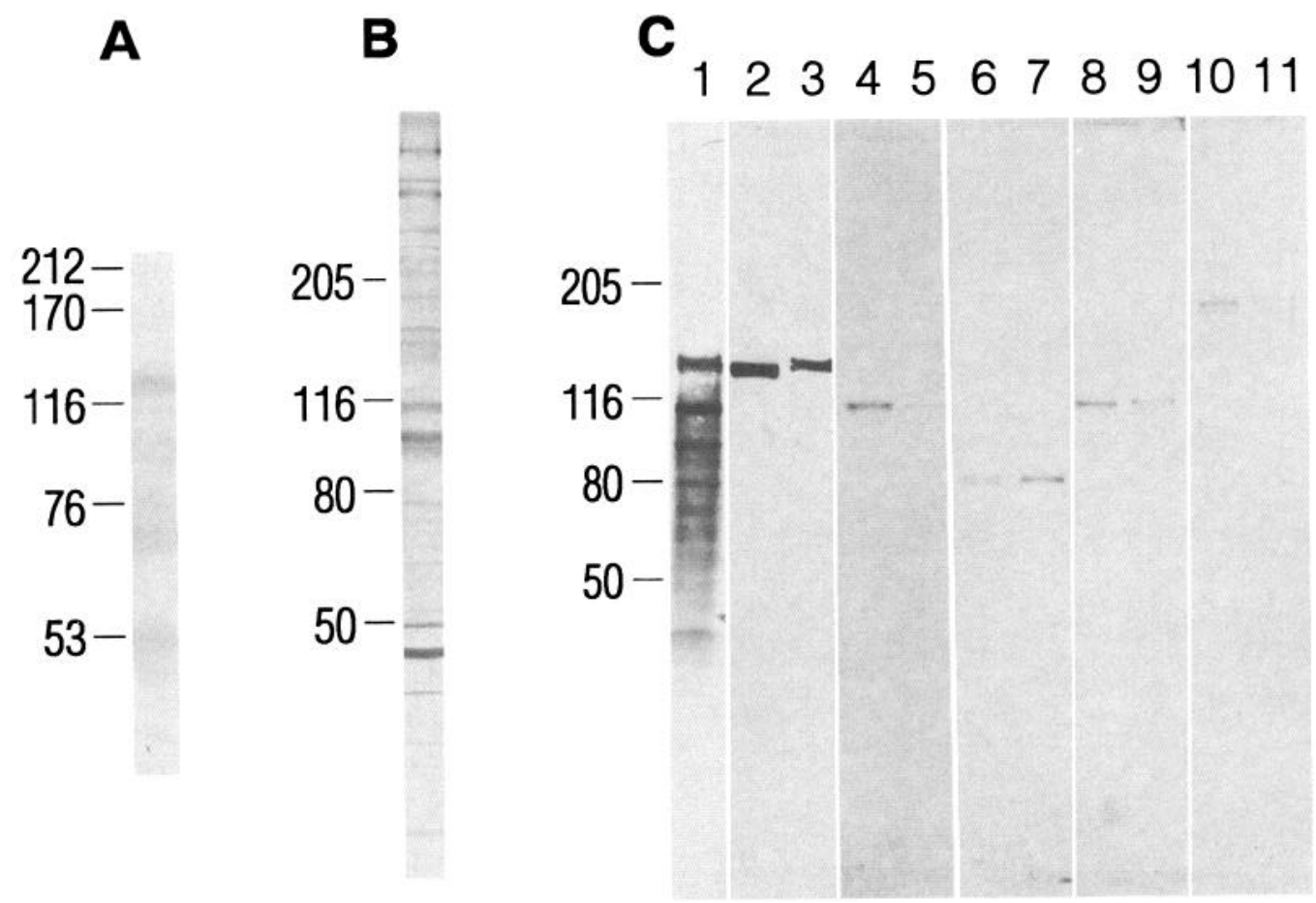

Figure 1. Characterization of Drosophila neuronal glycoproteins bearing the HRP carbohydrate epitope. A, Purified HRP proteins, separated by SDS-PAGE and stained with Coomassie brilliant blue. The upper, darkest band at about $135 \mathrm{kDa}$ is neurotactin. The next band down (110 kDa) is DPTP69D. The next two bands are in the $85 \mathrm{kDa}$ range; they do not always resolve well and are largely composed of neurotactin breakdown products, as only neurotactin sequence is generated from this molecular weight range. The band at the position of the $76 \mathrm{kDa}$ marker is fasciclin I. The fuzzy bands below this $(65$ and $60 \mathrm{kDa})$ are also primarily neurotactin breakdown products. $B$, A Western blot, using anti-HRP antiserum, of a Drosophila embryo lysate fractionated by SDS-PAGE (6-15\% gradient gel). Binding of the primary antibody was detected using alkaline phosphatase (AP)-conjugated secondary antibody and AP immunohistochemistry. $C$, Western blots of embryonic lysates (lanes 2, 4, 6, 8, 10) and of the purified HRP protein fraction (lanes 1, 3, 5, 7, 9, 11). Blots were probed with the indicated antibodies, followed by AP-conjugated secondary antibody. Lane 1, Probed with anti-HRP. The upper two dark bands correspond to neurotactin at $135 \mathrm{kDa}$ and DPTP69D at $110 \mathrm{kDa}$. Fasciclin I migrates with the $80 \mathrm{kDa}$ marker on this gel. The other dark bands above and below fasciclin I include neurotactin breakdown products. Note the similarity between this lane and the lane of $A$. Lanes 2 and 3, Probed with a mixture of the anti-neurotactin MAbs BP106 and FA4. These do not react with degradation products. Lanes 4 and 5, probed with anti-DPTP69D MAbs 3F11 and 3F12; Lanes 6 and 7, probed with anti-fasciclin I MAbs $2 \mathrm{~A} 2$ and 5H7; Lanes 8 and 9, probed with the anti-fasciclin II MAb 1D4; Lanes 10 and 11, probed with anti-neuroglian MAbs BP104 and 1B7. The positions of molecular weight markers are indicated at the left margins of $A-C$.

\section{Results}

\section{Purification and characterization of HRP proteins from}

Drosophila embryos

To characterize proteins bearing the HRP carbohydrate antigenic determinant, we initially fractionated lysates from 9-15hr-old Drosophila embryos on SDS-PAGE gels and analyzed them by Western blotting using anti-HRP antiserum. An example of such an experiment is shown in Figure $1 B$. Many discrete bands, ranging in apparent molecular weight from $>200$ $\mathrm{kDa}$ to $<40 \mathrm{kDa}$, are visualized.

To preparatively isolate the HRP proteins, we first fractionated anti-HRP antiserum by binding it to an column of pineapple bromelain, a glycoprotein that shares the same crossreacting carbohydrate epitope (Katz et al., 1988). This bound anti-carbohydrate antibody was eluted and used to make affinity columns. Lysates from 9-16-hr-old (stage 12-17; Campos-Ortega and Hartenstein, 1985) fly embryos were passed through the affinity columns, and bound glycoproteins bearing the HRP epitope were eluted at low $\mathrm{pH}$.

To remove nonglycoprotein contaminants from the HRP proteins, the anti-HRP column eluate was further purified by binding to concanavalin $\mathrm{A}$ (ConA)-agarose beads. The capacity of the anti-HRP columns was very low (see Materials and Meth- ods), so a typical preparative purification required pooling eluates from 12-20 anti-HRP column runs. This was done by sequentially binding anti-HRP column eluates to the same batch of ConA-agarose. The ConA-agarose step also served to concentrate the HRP proteins, because they are too dilute for gel fractionation after initial elution from the anti-HRP column. In the final step of purification, eluates from the ConA-agarose beads were fractionated by SDS-PAGE. A Coomassie blue-stained gel of such a preparation is shown in Figure 1A. In lane 1 of Figure $1 C$, a Western blot of a large-scale preparation using anti-HRP antibody is shown. The overall pattern of bands is similar to that observed by Coomassie blue staining (Fig. 1A). Note, however, that the distribution of the proteins among the various molecular weights is quite different between the purified HRP proteins (Figs. $1 A, C$ ) and the crude lysate analyzed by Western blotting with anti-HRP antibodies (Fig. 1B). This suggests that a subset of the HRP proteins are selectively purified by our antiHRP affinity columns.

The purified HRP proteins were separated by SDS-PAGE and transferred to nitrocellulose filters. Protein bands were excised and treated with trypsin in situ (Tempst et al., 1990), and tryptic fragments were separated by HPLC and sequenced. We obtained readable sequence from seven different bands, corresponding to molecular weights of approximately $135 \mathrm{kDa}, 110 \mathrm{kDa}, 85 \mathrm{kDa}$, 


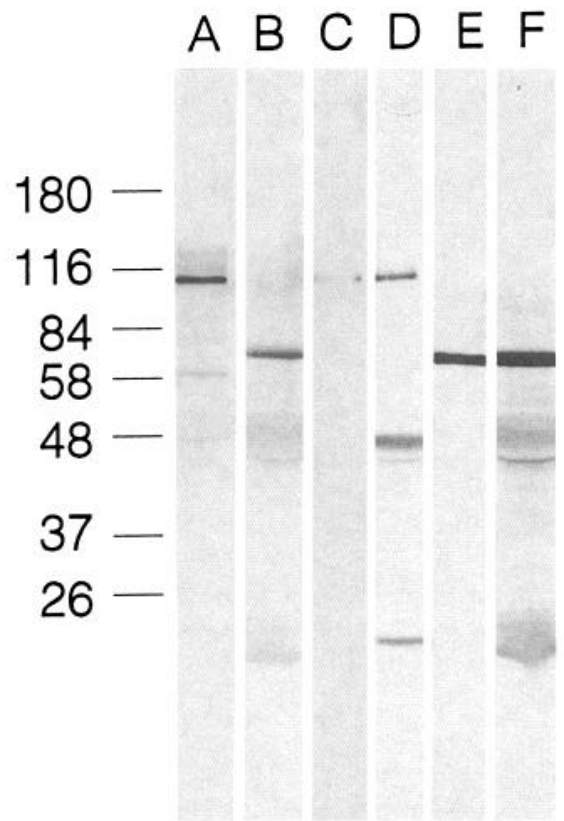

Figure 2. DPTP69D and fasciclin I bear the HRP carbohydrate epitope. Western blot analysis of immunoprecipitates and purified HRP proteins fractionated by SDS-PAGE. Antibodies used for immunoblotting were anti-HRP antiserum (lanes $A, B$ ), anti-DPTP69D MAbs $3 \mathrm{~F} 11$ and $3 \mathrm{~F} 12$ (lanes $C, D$ ), and anti-fasciclin I MAbs $2 \mathrm{~A} 2$ and $5 \mathrm{H} 7$ (lanes $E, F)$. Lanes $A$ and $D$ contain embryo lysates immunoprecipitated with a mixture of the anti-DPTP69D MAbs 1C2, 3D11, 3F12, 2C2, and 2B6, lanes $B$ and $F$ contain embryo lysates immunoprecipitated with a mixture of the anti-fasciclin I MAbs $5 \mathrm{H} 7,2 \mathrm{~A} 2,1 \mathrm{~B} 8$ and $5 \mathrm{E} 1$, and lanes $C$ and $E$ contain the purified HRP protein preparation. Antibody binding was detected using AP-conjugated secondary antibody and AP immunohistochemistry. The figure shows that the DPTP69D (lane $A$ ) and fasciclin I (lane B) bands precipitated from lysate with MAbs against the proteins and detected with anti-HRP antibodies comigrate with the bands detected in the immunoprecipitates (lane $D$ for DPTP69D and lane $F$ for fasciclin I) and in the purified HRP protein fraction (lane $C$ for DPTP69D and lane $E$ for fasciclin I) using the MAbs. The $50 \mathrm{kDa}$ and $25 \mathrm{kDa}$ bands detected in lanes $A, B, D$, and $F$ are the heavy and light chains of the IgGs used for immunoprecipitation. The positions of molecular weight markers are indicated at the left margin.

$75 \mathrm{kDa}, 70 \mathrm{kDa}, 65 \mathrm{kDa}$, and $60 \mathrm{kDa}$. Our sequence data define three glycoproteins as HRP protein species. Two fragments from a $75 \mathrm{kDa}$ band and one fragment from a $70 \mathrm{kDa}$ band yielded 10,13 , and 15 amino acid sequences that matched the known sequence of fasciclin I (Zinn et al., 1988; Table 1).

A second set of sequences were obtained from the major species migrating at $135 \mathrm{kDa}$. Three tryptic fragments produced sequences of 31,21 , and 11 residues that matched the known sequence of neurotactin, a heterophilic adhesion molecule (de la Escalera et al., 1990; Hortsch et al., 1990). We also obtained neurotactin sequence from protein bands migrating at $85 \mathrm{kDa}$, $75 \mathrm{kDa}, 70 \mathrm{kDa}, 65 \mathrm{kDa}$, and $60 \mathrm{kDa}$ (Table 1). This indicates that neurotactin is subject to extensive proteolysis.

We also obtained sequences from three tryptic fragments generated from a protein band migrating at $110 \mathrm{kDa}$ (Table 1). These sequences match the predicted sequence of an R-PTP known as DPTP (Streuli et al., 1989). The gene encoding DPTP maps to position 69D on the polytene chromosomes, so we have denoted this protein DPTP69D. This nomenclature is consistent with the naming of other Drosophila PTPs.

To verify that fasciclin I and DPTP69D actually bear the HRP epitope, we generated MAbs against the protein compo- nent of DPTP69D (see Materials and Methods) and used these, together with existing MAbs against fasciclin I protein, to precipitate fasciclin I and DPTP69D from embryo lysates. We then analyzed these immunoprecipitates by Western blotting with anti-HRP antiserum. As shown in lanes A and B of Figure 2, immunoprecipitated DPTP69D and fasciclin I can be detected by immunoblotting with anti-HRP. We could not perform the same experiment for neurotactin because the two available MAbs against the protein do not work in immunoprecipitation experiments (data not shown). However, since neurotactin corresponds to the most prominent band seen in anti-HRP Western blots of the purified preparation (Fig. $1 \mathrm{C}$ ), and is also the most abundant protein in the purified HRP protein preparation (Fig. $1 A$ ), it is unlikely to be a contaminant.

We examined the purified HRP protein preparation by Western blotting with MAbs against the three HRP proteins that we identified by protein sequencing. Figure $1 C$ shows that neurotactin, DPTP69D, and fasciclin I migrate at the positions of three of the major bands in the HRP protein preparation. Neurotactin breakdown products are not recognized by the available anti-neurotactin MAbs, so only one neurotactin band is visualized.

We also analyzed the purified preparation by Western blotting with MAbs against a number of other characterized adhesion and signal transduction molecules. Figure $1 C$ shows that fasciclin II and neuroglian recognize bands in the HRP protein preparation. Thus, these adhesion molecules are likely to bear the HRP epitope. Two other R-PTPs, DPTP10D and DPTP99A, could also be detected in the purified HRP protein preparation by Western blotting (data not shown), suggesting that they also bear the epitope.

\section{Expression of DPTP69D in Drosophila embryos}

Although DPTP69D cDNAs had been sequenced earlier (Streuli et al., 1989) the expression patterns of the protein and its mRNA had not been analyzed. To characterize the temporal expression pattern of DPTP69D mRNA, we performed Northern blotting experiments on staged embryo RNA preparations. These data show that a single $5.7 \mathrm{~kb}$ DPTP69D mRNA species is present throughout embryogenesis, and in adult flies (Fig. 3). The intense signal in the $0-3 \mathrm{hr}$ sample suggests that there is maternal contribution of DPTP69D mRNA.

To examine the spatial distribution of DPTP69D mRNA during embryogenesis, we used cDNA clones as probes in wholemount digoxigenin in sit $u$ hybridization experiments (Tautz and Pfeifle, 1989). Localized expression of DPTP69D mRNA is first detectable in stage 9-10 (germ band extended) embryos (Campos-Ortega and Hartenstein, 1985). In these embryos, the strongest hybridization is observed in the layer between the epidermis and the mesoderm (Fig. 4A, arrowhead). This cell layer contains neuroblasts and ganglion mother cells. Later in development, DPTP69D mRNA is enriched in the brain (Fig. $4 B$, arrow) and ventral nerve cord (Fig. $4 B$, arrowhead; $C$, arrow). There is also low-level expression of the mRNA in the epidermis.

To characterize the embryonic expression pattern of the protein, we used anti-DPTP69D MAbs to stain fixed embryo collections, using HRP/Ni immunohistochemistry for detection. DPTP69D is present on neuroblasts in the germ band extended embryo (stages 9-10). Axonal staining is first observed at the onset of germ band retraction (stage 12/5; data not shown). After this time, staining is primarily localized to CNS axons (Fig. $4 D, F, I)$. No staining of the axons of peripheral sensory neurons 


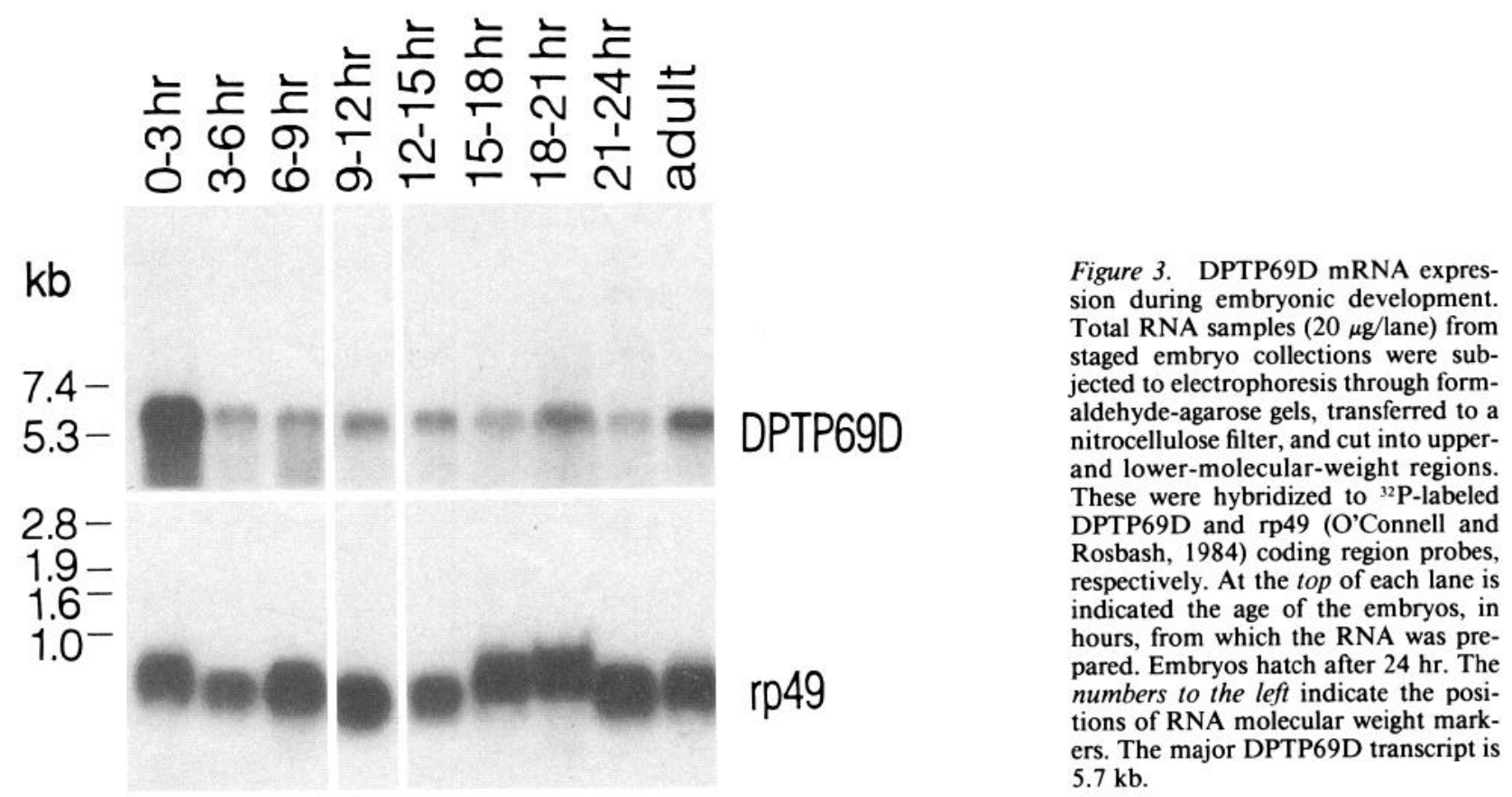

is observed, but motor axons can be visualized (Fig. $4 D$, thin arrow). This pattern of expression is very similar to that previously observed for the R-PTPs DLAR, DPTP10D, and DPTP99A (Hariharan et al., 1991; Tian et al., 1991; Yang et al., 1991). In addition to expression in the CNS, localized staining is also observed at muscle attachment sites in the epidermis of stage 15-16 embryos (Fig. $4 E$, arrowhead).

Figure 4 also displays embryonic nerve cords stained with anti-HRP (Fig. 4G), anti-neurotactin (Fig. 4H), and anti-fasciclin I antibodies (Fig. $4 J$ ). This allows a comparison of the total anti-HRP staining pattern with the pattern of expression of each of the major HRP proteins. Anti-HRP stains all neuronal cell bodies and axons in both the CNS and PNS. Neurotactin is expressed in a similar pattern to anti-HRP in the CNS, and in one subset of PNS neurons (de la Escalera et al., 1990; Hortsch et al., 1990). Fasciclin I is expressed on a subset of CNS axons and on some CNS cell bodies, as well as on all PNS axons and cell bodies (Zinn et al., 1988; McAllister et al., 1992). DPTP69D is expressed on CNS axons (Fig. 4I), but does not appear to be present on CNS cell bodies or in the PNS. Thus, the anti-HRP staining pattern could be characterized as the sum of the expression patterns of neurotactin, DPTP69D, and fasciclin I in the CNS, and of fasciclin I and neurotactin in the PNS. However, the Western blot analysis (Fig. $1 B$ ) suggests that there are many other HRP proteins that are not purified by our columns, and these could also contribute to the staining pattern.

\section{DPTP69D expression in the larval CNS and imaginal discs}

We examined DPTP69D expression in the nervous systems and imaginal discs of third instar larvae by MAb staining using HRP immunohistochemistry. Dark staining is observed in the neuropil of the central brain (Fig. $5 A, B$ ). The staining near the junction of the two brain lobes seen in the ventral view of Figure $5 \mathrm{~A}$ (solid arrow) is in the same region as the fiber tracts of the developing mushroom body lobes (Nighorn et al., 1991). However, analysis of the staining pattern in brains from the mushroom body-specific enhancer trap line M60 (provided by K.-A. Han and R. L. Davis, Baylor University) reveals that DPTP69D is not expressed on the processes of mushroom body neurons (data not shown). This analysis was performed using confocal microscopy and double-labeling for DPTP69D and $\beta$-galactosidase ( $\beta$-gal), which is localized to both neuronal cell bodies and processes in larvae from this line.

In each of the three thoracic ganglia, DPTP69D is expressed at high levels in the neuropil (Fig. 5D). Especially dark staining is observed in lateral regions (arrowhead), and processes extending from these regions to the midline are visible. DPTP69D is also localized to the $\mathrm{A} 8$ abdominal ganglion at the posterior extremity of the ventral nerve cord (arrow). Nerves connecting the leg and wing imaginal discs to the ventral cord are stained (data not shown). DPTP69D is also expressed on portions of the basal surface of imaginal disc epithelia, especially near attachment stalks (data not shown).

In the eye-antennal disc, DPTP69D is localized to photoreceptor axons in the optic stalk (Fig. $5 A, C$ ). The segments of these axons that course across the surface of the optic lobes express DPTP69D at high levels (Fig. 5E). Lower levels of DPTP69D are present on the terminal segments of the R7-R8 photoreceptor axons within the medulla (Fig. $5 H$ ).

\section{DPTP69D expression in the larval optic lobes}

Within the optic lobes, a columnar array of thick parallel processes express DPTP69D at high levels (Fig. 5C,F). These processes are adjacent to but distinct from the photoreceptor axons, as shown by double-labeling with antibodies recognizing photoreceptor axons and DPTP69D (Figs. 5G, 6A,B). This array of processes has been described (Kunes et al., 1993) as the transmedullary fibers of the developing lobula complex (TMFs). The TMFs are within the inner proliferation center (IPC), adjacent to a furrow that separates the oldest lamina neurons from IPC cells (Figs. 5G,6A). The IPC gives rise to the lobula complex and to the inner medulla (Selleck and Steller, 1991). Medial to the lamina, the TMFs join a DPTP69D-expressing hemiconical neuropil that may be the inner medulla neuropil (Fig. $6 \mathrm{C}$ ).

Within a crescent-shaped portion of the lamina, DPTP69D is expressed on fibers that run parallel to the photoreceptor 

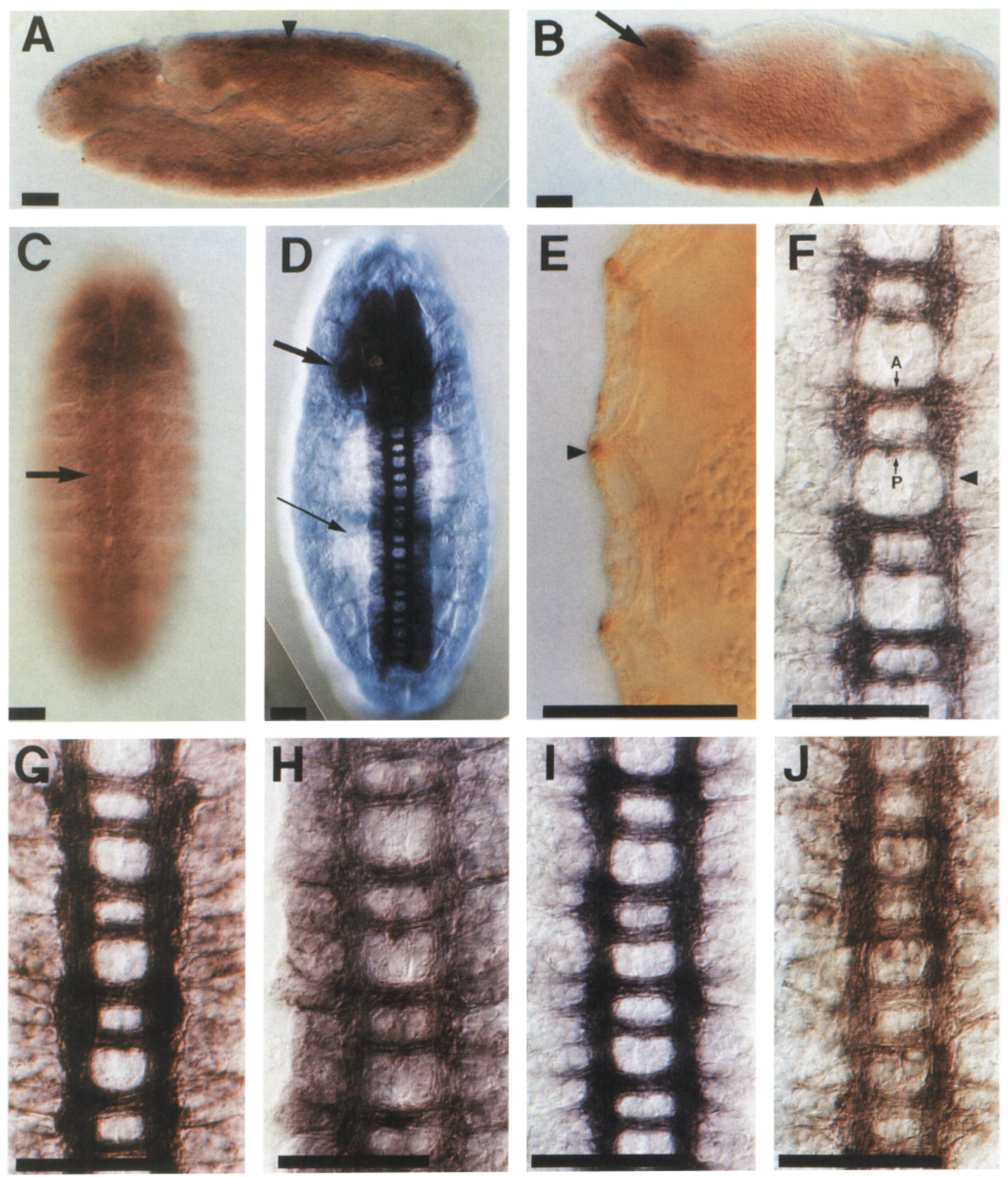
axons. The fibers forming the anterioventral edge of this crescent stain most intensely (Fig. 6A). Fibers in this region of the lamina are thought to be processes of newly differentiating neurons (Selleck and Steller, 1991). Medial to the lamina, these processes merge with a stained neuropil that may be the outer neuropil of the medulla. This neuropil is the outer layer of a two-layered crescent, which has an unstained region between the layers (Fig. $6 C$ ). The termini of the R7-R8 photoreceptor axons are located in the unstained region between the outer and inner medulla neuropils. The medullar neuropils also express DPTP69D in pupae (data not shown). These neuropils eventually develop into the distal and proximal plexuses of the adult optic medulla described by Meinertzhagen and Hanson (1993).

In more medial sections, a third neuropil nestled inside the other two also expresses DPTP69D. This layer may be the neuropil of the lobula complex (data not shown). DPTP69D expression is also prominent in a flat neuropil at the base of the lamina (Figs. $5 \mathrm{H}, 6 \mathrm{D}$ ), where the axons of photoreceptors R1R6 terminate (Selleck and Steller, 1991). Finally, DPTP69D staining is observed on an array of unidentified thin fibers that course over the surfaces of the optic lobes (Fig. $5 C$, small arrow).

\section{Discussion}

\section{Characterization of Drosophila HRP proteins}

The epitope recognized by anti-HRP in insects is a carbohydrate moiety shared by insect neuronal glycoproteins and certain plant glycoproteins (Snow et al., 1987; Katz et al., 1988). Kurosaka et al. (1991) concluded that the cross-reacting HRP epitope contains $\alpha 1-6$-linked mannose and $\alpha 1-3$-linked fucose residues attached to main-chain residues 1 and 3 of the sugar chain. However, it has not been shown that insect glycoproteins contain a carbohydrate chain with this structure.

To identify Drosophila neural glycoproteins bearing the HRP epitope, we purified proteins from embryo lysates that bound to an anti-HRP affinity column, and determined the sequences of peptides derived from seven different protein bands. These comprise the major bands in the molecular weight range between $135 \mathrm{kDa}$ and $60 \mathrm{kDa}$ (Fig. $1 \mathrm{~A}$; see Materials and Methods). Our sequences define three HRP protein species: fasciclin I ( $75 \mathrm{kDa})$, neurotactin $(135 \mathrm{kDa}, 85 \mathrm{kDa}, 75 \mathrm{kDa}, 70 \mathrm{kDa}, 65 \mathrm{kDa}, 60$ $\mathrm{kDa}$ ), and DPTP69D (110 kDa; Table 1). In addition, we examined the purified HRP protein preparation by Western blotting with a variety of other antibodies (Fig. 1C). These data suggest that fasciclin II, neuroglian, DPTP10D, and DPTP99A are also HRP proteins. Thus, several different cell adhesion and signal transduction molecules bear the HRP epitope. In a similar manner, the L2/HNK-1 carbohydrate moiety is found on many vertebrate adhesion molecules, including N-CAM, L1, and myclin-associated glycoprotein (Kruse et al., 1984).

The fasciclins and neuroglian are glycoproteins expressed on CNS and PNS axons, and may be involved growth cone extension and axon guidance. They are capable of functioning as homophilic adhesion molecules (reviewed by Grenningloh et al., 1990). Fasciclin II and neuroglian contain Ig and FN domains, and are closely related to the vertebrate adhesion molecules N-CAM and L1, respectively (Harrelson and Goodman, 1988; Bieber et al., 1989; Grenningloh et al., 1990, 1991). Fasciclin $I$ is a four-domain protein that is unrelated to other known adhesion molecules (Zinn et al., 1988). However, OSF-2, a human osteoblast protein related to fasciclin $\mathrm{I}$, has been recently described (Takeshita et al., 1993).

Our demonstration that Drosophila fasciclins I and II are HRP proteins agrees with earlier observations by Snow et al. (1987), who showed that grasshopper fasciclins I and II bear the HRP epitope. In both species, fasciclin I and II are also expressed outside the nervous system, on cells that do not stain with antiHRP antisera (Bastiani et al., 1987; McAllister et al., 1992). Furthermore, most of the fasciclin I and II purified from grasshopper embryos lacks the HRP epitope (Snow et al., 1987). Fasciclin I and II always contain carbohydrate (Snow et al., 1988; Wang et al., 1993), indicating that when expressed outside the nervous system, their carbohydrate chains do not contain the moieties recognized by anti-HRP antisera.

Neurotactin is a $135 \mathrm{kDa}$ heterophilic adhesion molecule expressed on CNS and PNS cell bodies and axons (Piovant and Lena, 1988; Barthalay et al., 1990; de la Escalera et al., 1990; Hortsch et al., 1990). Neurotactin is also expressed on epidermal cells at the germ band extended stage. Thus, like fasciclins I and II, neurotactin must exist in forms which do not bear the HRP epitope. Neurotactin is a type II transmembrane protein whose extracellular domain is related in sequence to cholinesterases. Only one form of neurotactin has been identified by cDNA sequencing (de la Escalera et al., 1990; Hortsch et al., 1990). Thus, it is likely that the $85 \mathrm{kDa}, 75 \mathrm{kDa}, 70 \mathrm{kDa}, 65 \mathrm{kDa}$, and $60 \mathrm{kDa}$ HRP proteins that we have identified as containing neurotactin sequences are proteolytic breakdown products of the $135 \mathrm{kDa}$ protein. Neurotactin contains 13 pairs of adjacent

Figure 4. Localization of DPTP69D mRNA, DPTP69D protein, neurotactin protein, fasciclin I protein, and the anti-HRP epitope in wholemount embryos and dissected ventral nerve cords. $A-C$, Localization of DPTP69D mRNA in whole-mount embryos. Embryos were hybridized to digoxigenin-labeled probe, and hybridization was detected using AP-conjugated anti-digoxigenin antibody and AP immunohistochemistry. This generates a brownish-purple reaction product in the areas where mRNA recognized by the probe is localized. $A$, Stage 10 embryo, lateral view. Dorsal is up and anterior is to the left in $A$ and $B$. The arrowhead indicates hybridization to the neuroblast/GMC layer. $B$, A lateral view of a stage 13 embryo. The arrowhead indicates hybridization to the ventral nerve cord. The arrow indicates hybridization in the developing brain. $C$, A ventral view of a stage 14 embryo. Anterior is up. The arrow indicates hybridization to neuronal cell bodies within the ventral nerve cord. $D$ and $E$, localization of DPTP69D protein in whole-mount embryos. DPTP69D was detected by staining with anti-DPTP69D MAbs 3F11 and 3F12, followed by HRP-conjugated secondary antibody and HRP/Ni immunohistochemistry. $D$, A ventral view of a stage 16 embryo. DPTP69D protein is expressed in the brain (thick arrow), on axons in the ventral nerve cord, and on motor axons that exit the CNS (thin arrow). E, A high-magnification view of the lateral epidermis of a stage 16 embryo. DPTP69D is expressed in dot-like patterns on the epidermis at segment boundaries (arrowhead). This expression pattern is likely to correspond to the longitudinal muscle attachment sites (apodemes); unstained muscle fibers are visible with Nomarski optics. HRP rather than HRP/Ni histochemistry was used here, so the reaction product is brown. $F-J$, High-magnification views, from the dorsal side, of segments of dissected nerve cords; anterior is up. Four segments are visible in each panel. $F$, Stage 13, anti-DPTP69D MAbs. The anterior and posterior commissures are labeled $A$ and $P$. A longitudinal connective is indicated by the arrowhead. $G$, Stage 15 , stained with anti-HRP antiserum. $H$, Stage 15, stained with anti-neurotactin (MAb BP106). I, Stage 15, stained with anti-DPTP69D. Note the absence of cell body staining with anti-DPTP69D MAbs (compare to $G$ and $H$ ). $J$, Stage 15, anti-fasciclin I (MAb 6D8). Scale bars: $A-D, 10 \mu \mathrm{m} ; E, 10 \mu \mathrm{m} ; F$, $10 \mu \mathrm{m} ; G-J, 10 \mu \mathrm{m}$. 

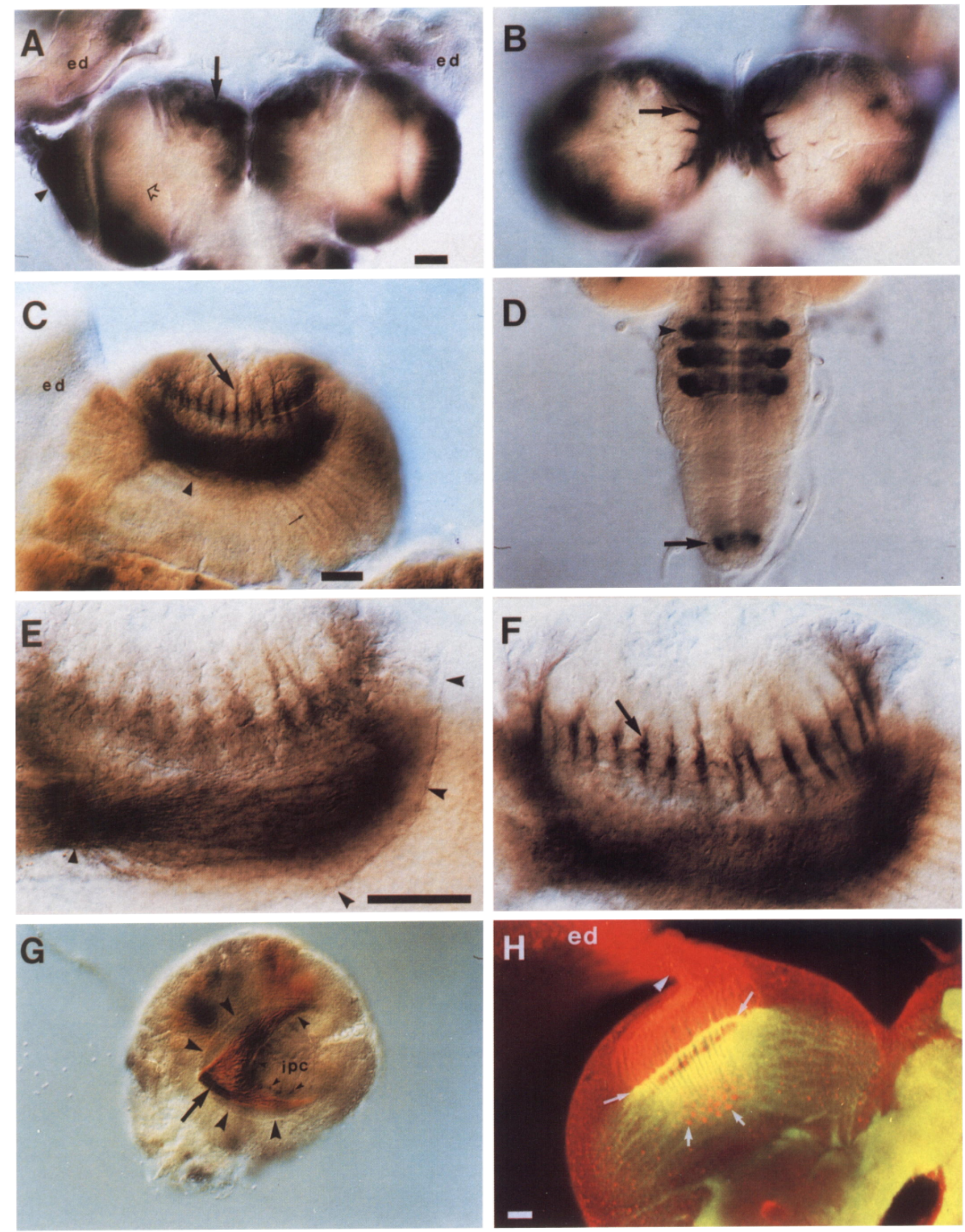
basic amino acids, which are often highly susceptible to protease activity. It also has two PEST sequences, which are characteristic of rapidly degraded proteins.

The R-PTPs DPTP10D and DPTP99A, which appear to be HRP proteins, are selectively expressed on CNS axons in the embryo (Hariharan et al., 1991; Tian et al., 1991; Yang et al., 1991). Here we show that DPTP69D is also primarily localized to CNS axons in stage 12-16 embryos (Fig. $4 D, F, I$ ). Early in embryogenesis, however, DPTP69D is expressed on many ectodermal cells, and in stage 15-16 embryos it is localized to muscle attachment sites in the epidermis (Fig. 4E). This ectodermal DPTP69D must also lack the HRP epitope. All of the axonal R-PTPs have extracellular regions that are homologous to neural adhesion molecules. DPTP10D and DPTP99A contain only FN repeats, while DPTP69D and DLAR have both Ig domains and FN repeats (reviewed by Zinn, 1993). Unlike the other Drosophila R-PTPs, a vertebrate counterpart of DPTP69D has not been described.

The localization of four of the five known Drosophila R-PTPs to CNS axons [DLAR, DPTP10D, DPTP69D, and DPTP99A are axonal; DPTP4E (Oon et al., 1993) is more generally expressed] suggests that the R-PTPs are components of a phosphotyrosine signaling pathway that functions during assembly of the axon array. This pathway could also involve the $a b l$ tyrosine kinase, which is expressed in embryonic CNS axons. Mutations in the $a b /$ gene, when combined with mutations in fasciclin I, disabled, and other genes, cause defects in axon pathway formation in the embryonic CNS (Gertler et al., 1989, 1993; Elkins et al., 1990; Henkemeyer et al., 1990).

How many other proteins bear the HRP epitope? In the studies of Snow et al. (1987), 17 or morc HRP protcin spots werc visualized by two-dimensional gel electrophoresis. Some of these spots, however, may be degradation products or differentially modified forms of other HRP proteins. Analysis of Drosophila embryo or larval lysates by Western blotting with anti-HRP (Katz et al., 1988; Fig. $1 B$ ), reveals many bands, some of which are $>135 \mathrm{kDa}$ that cannot be neurotactin breakdown products. Neuroglian, DPTP10D, and DPTP99A are all $>150 \mathrm{kDa}$, but more than three bands are visible in the upper region of the gel in Figure $1 B$.

We do not know whether the HRP carbohydrate epitope itself has a function in neural development. Two mutations exist that eliminate expression of the epitope. One mutation is on the TM3 balancer chromosome (Snow et al., 1987). The CNS and PNS of homozygous TM3 embryos have a normal appearance when stained with other antibody markers. The second mutation, nac, which eliminates expression of the epitope only in imaginal tissues, is homozygous viable (Katz et al., 1988). In nac mutants, there appear to be abnormalities in the pathways taken by the axons of wing disk sensory neurons as they approach the CNS (Whitlock, 1993).

\section{Expression of DPTP69D in the larval optic lobes}

DPTP69D is localized to a subset of neuronal processes in the larval brain and segmental ganglia (Fig. $5 A, B, D$ ). It is also expressed on photoreceptor axons within the optic stalk (Fig. $5 A, C, E)$. In the optic lobes, DPTP69D is expressed at high levels on a columnar arc of parallel thick bundles (Fig. $5 C, F$ ). These bundles have been denoted "transmedullary fibers of the developing lobula complex" by Kunes et al. (1993), and are adjacent to the lamina (Fig. $5 G$ ).

DPTP69D is also expressed in a set of three nested, hemiconical neuropils (Fig. 6A,C). These are likely to be the outer and inner medullar neuropils and the neuropil of the lobula complex. The outer medullar neuropil receives synaptic input from the lamina, and develops into the distal medullar plexus of the adult fly. The inner medullar neuropil is contiguous with the TMFs, and develops into the proximal medullar plexus. The

Figure 5. DPTP69D protein expression in the CNS of third-instar larvae. DPTP69D protein (black staining in $A \cdots G$, green staining in $H$ ) was visualized using the 3 F1 1/3F12 MAb, followed by HRP-conjugated second antibody and DAB/Ni immunohistochemistry $(A-G)$, or FITC-conjugated secondary antibody and confocal microscopy $(H)$. In $G, \beta$-gal was also visualized by MAb staining (brown). In $H$, $\beta$-gal was visualized using rabbit anti- $\beta$-gal sera and RITC-conjugated secondary antibodies. $A$, Ventral view of the brain hemispheres, with attached eye disks (ed). Anterior is up. Arrowhead indicates DPTP69D expression on photoreceptor axons in the optic stalk and as they fan out over the surface of the optic lobes. The region of the medullar neuropils is indicated by the open arrow. The solid arrow indicates a large group of staining fibers in the central brain. The fibers of the developing mushroom body lobes are also located in this region (see Nighorn et al., 1991). B, A dorsal view of the same brain hemispheres (anterior is up). The arrow indicates one of the three large fiber bundles that emanate from the central neuropil. $C$, A ventral view of a brain hcmisphere, with an attached eye disk $(e d)$. Anterior is to the left, and the lateral surface of the brain hemisphere is on top. The arrow indicates the parallel array of thick fibers in the optic lobe. The arrowhead indicates a region expressing DPTP69D at high levels. The upper layer in this region is composed of photoreceptor axons coursing across the surface of the optic lobe (see $E$ ), and the underlying layers are the neuropils of the lamina and medulla. The small arrow indicates one of the unidentified parallel thin processes on the surface of the optic lobe that express DPTP69D. $D$, A dorsal view of the ventral nerve cord. Anterior is up. The arrowhead indicates DPTP69D expression in the neuropil of the prothoracic ganglion. Note commissural processes expressing DPTP69D. Arrow indicates staining in the A8 abdominal ganglion. $E$ and $F$, Highmagnification ventrolateral views of the optic lobe, in two different focal planes. Anterior is to the left. $E$ shows a more superficial focal plane; the photoreceptor axons in the optic stalk can be clearly visualized (small arrowhead). Large arrowheads denote the fissure separating newly born lamina cells from mitotically active lamina precursor cells. $F$ shows a deeper focal plane, revealing the columnar array of parallel thick fibers in the central plug, derived from the inner proliferation center (arrow). The deep out-of-focus staining at the bottom is the medullar neuropils. $G$, A lateral view of an optic lobe, with the eye disk dissected away. Anterior is to upper left. The brownish photoreceptor axons (arrow) spread out over the surface of the lamina. The lamina neurons are within a crescent-shaped region that is separated from the lamina precursor cells by an anterior furrow (large arrowheads), and from the inner proliferative center (ipc) by a posterior furrow (medium arrowhead). DPTP69D-expressing fibers that are visualized in cross section within the ipc (small arrowheads) correspond to the columns seen in $C$ and $F$ (arrows). The out-of-focus staining is from decper central brain structures. $H$ is a ventral confocal image of photoreceptor axons $(r e d)$ and DPTP69D-expressing fibers $(g r e e n)$. Anterior is to the lower left. Photoreceptor axons originate in the eye disk (ed) and enter the optic lobe via the optic stalk (arrowhead). The yellow color in the optic stalk and lateral surface of the optic lobe indicates that the photoreceptor axons express DPTP69D. The bright yellow band (long arrows) underlying the lamina neurons is a cross section of the plate-like region where the axons from photoreceptors R1-R6 form their terminal arbors. The DPTP69D staining in this area may derive from the photoreceptor axons or from lamina neuron processes. The R7 and R8 photoreceptor axons terminate in the medulla (short arrows). The reddish color of these round endings indicates that they express DPTP69D at lower levels relative to $\beta$-gal than do the more proximal regions of the axons, which have a yellow-green tinge. Scale bars: $A, 10 \mu \mathrm{m}$ for $A, B, D$, and $G ; C ; 10$ $\mu \mathrm{m} ; E, 10 \mu \mathrm{m}$ for $E$ and $F ; H, 5 \mu \mathrm{m}$. 

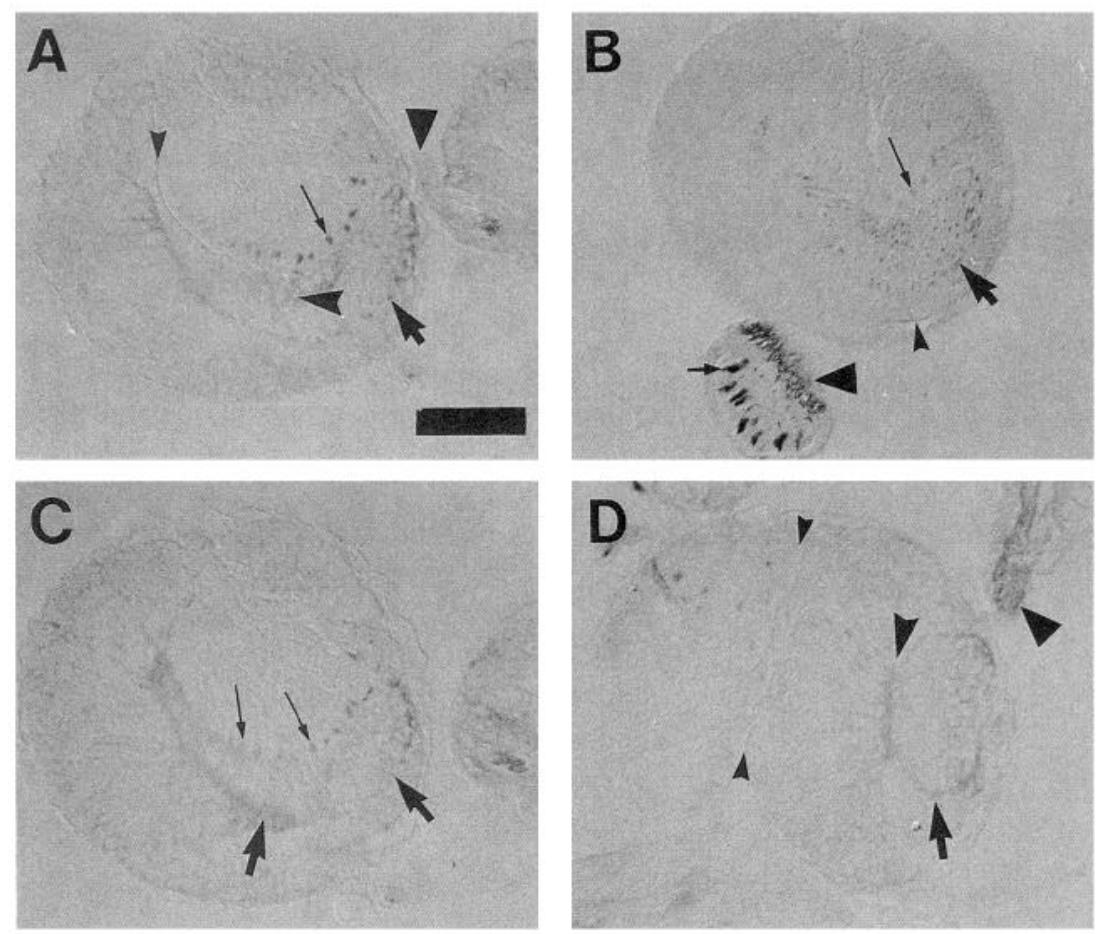

Figure 6. Pattern of DPTP69D expression in relation to photoreceptor axons in sections from third instar larval brains. In $A-D$, DPTP69D protein was visualized using the $3 \mathrm{D} 11 \mathrm{MAb}$, followed by HRP-conjugated second antibody and $\mathrm{DAB} / \mathrm{Ni}$ immunohistochemistry. In $B$, the photoreceptor axons were also visualized, using a Promega anti- $\beta$-gal MAb followed by HRP-conjugated second antibody and DAB/Ni immunohistochemistry. $A-C$, Longitudinal sections of larval brains at a section plane near the base of the lamina. Anterior is to the lower right, ventral to the lower left. $A$ and $C$ are sections from the same brain, with $A$ more lateral than $C$. $A$, DPTP69D expression on photoreceptor axons is apparently higher in the optic stalk (triangle, $A$; also in $D$ ) than within the lamina [compare the punctate photoreceptor axon staining in the lamina (region between the large and small arrows) in $B$ with the more diffuse DPTP69D staining in $A$ ]. DPTP69D staining is intense in the curving anteroventral-most row of fascicles (large arrows) two to four cells from the border between the lamina and the lamina precursor cells (arrowhead in $B$ ). These fascicles may be newly forming lamina columns. The thick bundles of the DPTP69D-expressing TMFs (small arrows) are separated from the oldest neurons of the lamina by a furrow (small arrowhead). The area of terminal arborization of axons from photoreceptors R1-6 also expresses DPTP69D (large arrowhead). B, Anti- $\beta$-gal stained photoreceptors (small arrow) send axons (triangle) via the optic stalk into the developing lamina, where they are visible in cross section (large arrow). The furrow (arrowhead) separates the lamina precursors from their postmitotic descendants. The thick fibers (TMFs) expressing DPTP69D (long arrow) can be seen in the ipc, adjacent to the lamina. DPTP69D staining on the TMFs is much fainter than in $A$, because the section was allowed to react only long enough to clearly visualize the much more abundant $\beta$-gal antigen. $C$, In this plane of section (medial to the terminal arborization of the R1-R6 photoreceptor axons), the anteroventral-most row of DPTP69D-expressing fascicles from the lamina that are visualized in $A$ (right-hand large arrow in C) appears to merge with the neuropil of the outer medulla (left-hand large arrow). Similarly, the TMFs appear to merge with the neuropil of the inner medulla (small arrows). $D$, A horizontal section showing the furrow dividing the optic lobe from the central brain (small arrowheads). DPTP69D-expressing photoreceptor axons can be seen in the optic stalk (triangle). The DPTP69D-expressing plate-like region where axons from photoreceptors R1-6 arborize is seen in cross-section (large arrowhead), and is contiguous with the curving rows of DPTP69D-expressing fascicles in the lamina (arrow). Scale bar, $10 \mu \mathrm{m}$

The R7 and R8 photoreceptor axons terminate in the region between the processes of these neuropils that are visualized by DPTP69D staining.

Within the lamina, the level of DPTP69D expression appears to be highest near the ventral edge, which is where the processes of the most recently differentiated lamina neurons are located (Fig. 6A). Photoreceptor axons first express markers of terminal differentiation such as chaoptin (and $\beta$-galactosidase in the M60 line; Fig. $6 B$ ) within this region (Kunes et al., 1993). This suggests that DPTP69D could be involved in process outgrowth by lamina neurons, and/or in the formation and rearrangement of synapses among these neurons and the R1-R6 photoreceptor axons.

\section{References}

Barthalay Y, Hipeau-Jacquotte R, de la Escalera S, Jiménez F, Piovant M (1990) Drosophila neurotactin mediates heterophilic cell adhesion. EMBO J 9:3603-3609.
Bastiani MJ, Harrelson AL, Snow PM, Goodman CS (1987) Expression of fasciclin I and II glycoproteins on subsets of axon pathways during neuronal development in the grasshopper. Cell 48:745-755.

Bieber AJ, Snow PM, Hortsch M, Patel NH, Jacobs JR, Traquina ZR, Schilling J, Goodman CS (1989) Drosophila neuroglian: a member of the immunoglobulin superfamily with extensive homology to the vertebrate neural adhesion molecule L1. Cell 59:447-460.

Campos-Ortega JA, Hartenstein V (1985) The embryonic development of Drosophila melanogaster. Berlin: Springer.

de la Escalera S, Bockamp E, Moya F, Piovant M, Jiménez F (1990) Characterization and gene cloning of neurotactin, a Drosophila transmembrane protein related to cholinesterases. EMBO J 9:3593-3601.

Elkins T, Zinn K, McAllister L, Hoffmann FM, Goodman CS (1990) Genetic analysis of a Drosophila neural cell adhesion molecule: interaction of fasciclin $I$ and Abelson tyrosine kinase mutations. Cell 60:565-575.

Gertler FB, Bennett RL, Clark MJ, Hoffmann FM (1989) Drosophila $a b l$ tyrosine kinase in embryonic CNS axons: a role in axonogenesis is revealed through dosage-sensitive interactions with disabled. Cell 58:103-113.

Gertler FB, Hill KK, Clark MJ, Hoffmann FM (1993) Dosage-sensitive modifiers of Drosophila abl tyrosine kinase function: prospero, 
a regulator of axonal outgrowth, and disabled, a novel tyrosine kinase substrate. Genes Dev 7:441-453.

Grenningloh G, Bieber AJ, Rehm EJ, Snow PM, Traquina Z, Hortsch M, Patel NH, Goodman CS (1990) Molecular genetics of neuronal recognition in Drosophila: evolution and function of immunoglobulin superfamily cell adhesion molecules. Cold Spring Harbor Symp Quant Biol 55:327-340.

Grenningloh G, Rehm EJ, Goodman CS (1991) Genetic analysis of growth cone guidance in Drosophila: fasciclin II functions as a neuronal recognition molecule. Cell 67:45-57.

Hariharan I, Chuang P-T, Rubin GM (1991) Cloning and characterization of a receptor-class phosphotyrosine phosphatase gene expressed on central nervous system axons in Drosophila melanogaster. Proc Natl Acad Sci USA 88:11266-11270.

Harrelson AL, Goodman CS (1988) Growth cone guidance in insects: fasciclin II is a member of the immunoglobulin superfamily. Science 242:700-708.

Henkemeyer MJ, West SR, Gertler FB, Hoffman FM (1990) A novel tyrosine kinase-independent function of Drosophila abl correlates with proper subcellular localization. Cell 63:949-960.

Hortsch M, Goodman CS (1990) Drosophila fasciclin I, a neural cell adhesion molecule, has a phosphatidylinositol lipid membrane anchor that is developmentally regulated. J Biol Chem 265:15 104-15109.

I Iortsch M, Patel N, Bieber AJ, Traquina ZR, Goodman CS (1990) Drosophila neurotactin, a surface glycoprotein with homology to serine esterases, is dynamically expressed during embryogenesis. Development 110:1327-1340.

Jan LY, Jan YN (1982) Antibodies to horseradish-peroxidase as specific neuronal markers in Drosophila and in grasshopper embryos. Proc Natl Acad Sci USA 79:2700-2704.

Katz F, Moats W, Jan YN (1988) A carbohydrate epitope expressed uniquely on the cell surface of Drosophila neurons is altered in the mutant nac (neurally altered carbohydrate). EMBO J 11:3471-3477.

Kruse J, Mailhammer R, Wernecke H, Faissner A, Sommer I, Goridis C, Schachner M (1984) Neural cell adhesion molecules and myelinassociated glycoprotein share a common carbohydrate moiety recognized by monoclonal antibodies L2 and HNK-1. Nature 316:146148.

Kunes S, Wilson C, Steller H (1993) Independent guidance of retinal axons in the developing visual system of Drosophila. J Neurosci 13: $752-767$.

Kurosaka A, Yano A, Itoh N, Kuroda Y (1991) The structure of a neural specific carbohydrate epitope of horseradish-peroxidase recognized by anti-horseradish peroxidase antiserum. J Biol Chem 266: $4168-4172$.

McAllister L, Goodman CS, Zinn K (1992) Dynamic expression of the cell adhesion molecule fasciclin I during embryonic development in Drosophila. Development 115:267-276.

Meinertzhagen IA, Hanson TE (1993) The development of the optic lobe. In: The development of Drosophila melanogaster (Bate M, Martinez-Arias A, eds), pp 1363-1492. Cold Spring Harbor, NY: Cold Spring Harbor Laboratory.

Nighorn A, Healy MJ, Davis RL (1991) The cyclic AMP phosphodiesterase encoded by the Drosophila dunce gene is concentrated in the mushroom body neuropil. Neuron 6:455-467.

O'Connell P, Rosbash M (1984) Sequence, structure, and codon preference of the Drosophila ribosomal protein 49 gene. Nucleic Acids Res 12:5495-5513.

Oon SH, Hong A, Yang XH, Chia W (1993) Alternative splicing in a novel tyrosine phosphatase gene (DPTP4E) of Drosophila-mela- nogaster generates 2 large receptor-like proteins which differ in their carboxyl termini. J Biol Chem 268:23964-23971.

Piovant M, Lena P (1988) Membrane glycoproteins immunologically related to the human insulin receptor are associated with presumptive neuronal territories and developing neurones in Drosophila melanogaster. Development 103:145-156.

Pulido D, Campuzano S, Koda T, Modolell J (1992) Dtrk, a Drosophila gene related to the trk family of neurotrophin receptors, encodes a novel class of neural cell-adhesion molecule. EMBO J 11:391-404.

Saiki RK, Gelfand DH, Stoffel S, Scharf SJ, Higuchi R, Horn GT, Mullis KB, Erlich HA (1988) Primer-directed amplification of DNA with a thermostable DNA polymerase. Science 239:487-491.

Sambrook J, Fritsch EF, Maniatis T (1989) Molecular cloning: a laboratory manual, 2d ed. Cold Spring Harbor, NY: Cold Spring Harbor Laboratory.

Selleck SB, Steller H (1991) The influence of retinal innervation on neurogenesis in the first optic ganglion of Drosophila. Neuron 6:8399.

Snow PM, Patel NH, Harrelson AL, Goodman CS (1987) Neuralspecific carbohydrate moiety shared by many surface glycoproteins in Drosophila and grasshopper embryos. J Neurosci 7:4137-4144.

Snow PM, Zinn K, Harrelson AL, McAllister L, Schilling J, Bastiani MJ, Makk G, Goodman CS (1988) Characterization and cloning of fasciclin I and fasciclin II glycoproteins in the grasshopper. Proc Natl Acad Sci USA 85:5291-5295.

Streuli M, Krueger NX, Tsai AYM, Saito H (1989) A family of receptor-linked protein tyrosine phosphatases in humans and Drosophila. Proc Natl Acad Sci USA 86:8698-8702.

Studier FW, Rosenberg AH, Dunn JJ, Dubendorff JW (1990) Use of T7 RNA polymerase to direct expression of cloned genes. Methods Enzymol 185:60-89.

Takeshita S, Kikuno R, Tezuka K, Amann E (1993) Osteoblast-specific factor 2: cloning of a putative bone adhesion protein with homology with the insect protein fasciclin I. Biochem J 294:1-8.

Tautz D, Pfeifle C (1989) A nonradioactive in situ hybridization method for the localization of specific mRNAs in Drosophila embryos reveals a translational control of segmentation gene hunchback. Chromosoma 98:81-85.

Tempst P, Link A, Riviera LR, Fleming M, Elicone C (1990) Internal sequence analysis of proteins separated on polyacrylamide gels at the submicrogram level: improved methods, applications and gene cloning strategies. Electrophoresis 11:537-553.

Tian S-S, Tsoulfas P, Zinn K (1991) Three receptor-linked proteintyrosine phosphatases are selectively expressed on central nervous system axons in the Drosophila embryo. Cell 67:675-685.

Wang W-C, Zinn K, Bjorkman PI (1993) Expression and structural studies of fasciclin $\mathrm{I}$, an insect cell adhesion molecule. J Biol Chem 268:1448-1455.

Whitlock KE (1993) Development of Drosophila sensory neurons in mutants with missing or modified surface molecules. Development $117: 1251-1260$.

Yang X, Seow KT, Bahri SM, Oon SH, Chia W (1991) Two Drosophila receptor-like tyrosine phosphatase genes are expressed in a subset of developing axons and pioneer neurons in the embryonic CNS. Cell 67:661-673.

Zinn K (1993) Drosophila protein tyrosine phosphatases. Semin Cell Biol 4:397-401.

Zinn K, McAllister L, Goodman CS (1988) Sequence analysis and neuronal expression of fasciclin I in grasshopper and Drosophila. Cell 53:577-587. 